\title{
Tokimeki Memorial Girl's Side: Enacting femininity to avoid dying alone
}

\section{Tina Richards}

\begin{abstract}
This paper examines the Japanese dating simulator video game, Tokimeki Memorial Girl's Side, the first female protagonist version in the Tokimeki Memorial series. Analysis of the game mechanics, characterisations, player options and their results demonstrate that the game assumes and reinforces a range of cultural norms and social expectations in relation to gender performativity, courting and dating, relationships and intimacy. I discuss how the gameplay actively produces particular heteronormative perspectives on how girls and young women should enact femininity if they are to avoid being alone at the end of the game, and, for that matter, in life.
\end{abstract}

\section{Keywords}

Dating Sim, Tokimeki Memorial, Otome, Gender, Techno-intimacy, video games

\section{INTRODUCTION}

In the ever-growing globalised market for video games, those produced for particular cultures and language groups are increasingly finding international audiences as internet sales and greater opportunities to travel provide access to games initially conceived and promoted as regionally exclusive. Games can become popular regardless of apparent limitations of language and culture. For example, with roughly $19 \%$ of the Australian population considered bilingual (Griffith 2014) and over 1.4 million students undertaking second language learning (Lo Bianco 2009), a considerable 
proportion of Australians can readily consume cultural product from non-Anglo sources. In any case, widespread familiarity with genre conventions among gamers means that even players who do not share a game's language can nevertheless engage in an enjoyable level of play. Further, in the context of globalised fandom, an appetite for Japanese popular culture means that video games popular in Japan are attractive to Australian players, even when untranslated. It seems important for Australian game studies to pay attention to the impacts and implications of games not available in English yet increasingly popular among Australian players, and equally important to take an interest in such games in relation to their own cultural contexts.

This paper examines the Japanese dating simulator video game, Tokimeki Memorial Girl's Side (Konami 2002), the first female protagonist version in the popular Tokimeki Memorial series. Like many dating simulators, the game remains officially unavailable in languages other than Japanese (although fan translations exist). Widely consumed by Japanese men and women, and especially popular among young people, dating simulators are a single- player game requiring the player to be the protagonist, either a male or female character chosen from those offered by the game, whose aim is to court one of a considerable number of possible suitors, also provided. In Tokimeki Memorial Girl's Side the suitor options include seven fellow high school students including students from the player/protagonist's own grade as well as upper or lower classmen or kōhai and senpai. Most interesting though is the inclusion of two further courting options, both her homeroom teacher and the principal. Heteronormative ideologies are most visible in the fact that all suitors are male. In order to court a suitor, the player must make both conversational choices and decisive actions, each of which are allocated points. Choices, depending on their positive or negative connotations within the situation can have points awarded or subtracted from the score.

Dating simulators usually have a set time frame at the end of which the points received will determine the outcome of the game. The Tokimeki Memorial Girl's Side game time spans three years of senior 
high school and both the passage of time and activities are depicted through the use of a calendar. The calendar is a main feature allowing the player to consider future events and plan her activities for the week. Once she determines an activity it is completed from Monday until Saturday, or on Sundays alone. Each day or sequence of days is shown as a short animated clip of the activity, followed by the game awarding/deducting points on the basis of what the player achieves. The calendar encourages the player to engage in mainstream social expectations as if she is living the everyday life of a Japanese girl of secondary school age through choices that reflect the real world such as studying, doing art, club activities, fitness, fashion, personal grooming and friends. These activities, while replicating the "real world," at the same time build stats that determine the player's chances of attracting the suitor she prefers.

Analysis of the game mechanics, characterisations, player options and their results demonstrate that the game assumes and reinforces a range of cultural norms and social expectations in relation to gender performativity, courting and dating, relationships and intimacy. I will argue that the gameplay actively produces particular heteronormative perspectives on how girls and young women should enact femininity if they are to avoid being alone at the end of the game. Since the game is from a female protagonist point of view and aimed at a female audience, I will use the female pronoun when referring to the player, this being said, both men and women may enjoy/play this game and it is in no way restricted only to women.

\section{Japan, Women and Intimacy}

The sole purpose of Tokimeki Memorial Girl's Side, as far as the mechanics of winning and losing are concerned, is to successfully woo a suitor and live happily ever after. The player must create a relationship and maintain it till the game ends. The game's content and mechanics replicate intimacy in the "real" world of Japanese society. If the player is not agreeable and submissive to male characters, they will be considered undesirable and will "end up" alone. The game will end with the player achieving no success in 
dating. She is depicted as alone and lonely, with only her younger brother Tsukushi to console her. In these ways, the game actually does replicate the (harsh) realities of still strong traditional attitudes to establishing heterosexual relationships, and the centrality of men in Japanese cultural life.

Traditionally, in Japan, women have been regarded as inferior to men and kept in subordinate positions by patriarchal family patterns (Masako 1995). According to Iwao (2007), recent trends indicate that young Japanese women are currently living at home longer with their parents rather than getting married straight away. Living at home means that they have the freedom to work/play until late and have their cleaning done and their meals prepared by their mothers (Iwao 2007). Once a woman wants to marry, or is expected to become a wife, she loses freedom and gains responsibility and expectations. This game introduces these (apparently inevitable) sacrifices at a young age as if to prepare female players for their unavoidable destinies as women. The game's content encouraging female players to conform to male ideals of desirable as well as submissive behaviour in order to be liked and loved is not at all surprising in the context of conventional and, indeed, contemporary Japanese cultural values and social experience. Most young women do expect to have to become somebody's wife, and in doing so, to lose much of the autonomy they might have experienced in their previous life in their family or in their own apartments and their professional careers.

In Japan, unmarried women are often referred to as Christmas Cakes (Japanese123 website 2005). Christmas cakes, as the name suggests, are special cakes that Japanese people eat traditionally at Christmas. They are not the fruit loaded, heavy textured, long lasting cakes of Western Christmases. These are short-lived cakes - good for 25 December only. The analogy goes that women are like Christmas cakes, perfect at 25 and spoiled the next day: that is, women older than 25 are past their "use-by" dates. It's as if the time limit within the game (3 years) along with 9 suitors and no more, is a reflection of a society in which women are on a ticking clock with limited potential 
partners - they either pick one and settle or are "waste" after they reach their expiry date.

\section{The Intricacies of Dating}

Most of the game mechanics revolve around the date event, which is, after all, the rationale for the play - all the routines of day to day life in one way or another converge in the narrative momentum and emotional engagement provided by the date. The experience of a Tokimeki Memorial Girl's Side date from the player's point of view consists of five major game mechanics in the following sequence: the selection of an outfit and accessories; her date's reaction to her clothing choices; the completion of the main date component, such as a meal or a movie; a question regarding her impression of the date; and her date's response to her answer to that question.

When a player chooses to advance to a date, she must first choose her outfit. Her choices of available clothing and accessories are based on her previous player shopping patterns - an activity available on the weekends in the game calendar. An experienced player will learn to shop early and often so that she accumulates a wider choice of outfits in readiness for a date. A player's/protagonist's capacity to advance in the game depends on choosing an outfit to wear on the date, and in order to have a sufficient choice of outfits, she is expected to have been shopping on weekends. There is an obvious question here about why the player must go shopping rather than simply having all the options available on the selection screen. After all, in terms of game play, it's the choice that matters. Nevertheless, the game assumes that the player will delight in shopping up a virtual storm, and clothing their avatar. It is, of course, the case that many women do enjoy shopping, and vast amounts of marketing are directed towards inviting them to continue to enjoy it as frequently as possible. Research indicates that when it comes to online shopping women surpassed men well over a decade ago (Girard et al. 2003). Publication of such data adds a factual air to the stereotype that women enjoy shopping - except that the stereotype relies also on an unspoken essentialist position that women enjoy shopping because 
they are women. Thus, shopping is assumed to occupy a cultural role as a trivial, feminised pastime. Walkerdine (1989, p. 1) stated in her opening to Femininity as Performance, "Femininity is seen as a series of roles often imposed by agents of socialization.” The gameplay indicates that shopping is a central activity in a woman's life. The player is required to shop in order to have sufficient outfit choices for dates, and although this can be seen as a virtual replication of the "real" world, it panders to the stereotype that women enjoy shopping and are interested in clothes and fashion. In fact, the game consistently provides the female player with a representation of what is expected of her gender in the "real" world. In this instance, the expectation is that women enjoy shopping and therefore on each weekend in the calendar the game offers a platform for shopping to be learned as a normalised and normative aspect of women's behaviour. The game mechanics reinforce this: the player/protagonist who wants to "succeed" in the game will perform her gender through shopping with careful thought about how her shopping behaviours will later impact on her dating points.

In a clear example of how gender performance, in Judith Butler's (2006) sense, becomes part of the embodied, affective experience of women. The stereotype that women enjoy shopping is built into the game mechanics along with the equally gendered assumption that women dress to please men. For the young female player this enactment of shopping behaviours as an aspect of gender performativity is likely to reinforce a range of pre-existing social and cultural assumptions about women and shopping that she has already learned or is currently learning. Indeed, she may well be using the game to help her learn “the rules” of women's heteronormative gender performance in the context of dating - that is, in the context of relationships with men. The latter is more likely to be the case among young Japanese women than among young Australians due to the constant affirmation of the Japanese cultural setting through school hierarchies, cultural activities, language use, etc., which to a Japanese audience would reflect the norm, but to an Australian audience be considered foreign. Although this may be less likely to 
affect Australians, some young Australian players may be encouraged to form particular attitudes.

In selecting what to wear, the player has the opportunity to obtain bonus points based on demonstrating an awareness of styles. For example, a particular blouse and skirt may attract points because it is considered to be elegant, but the same skirt with a t-shirt may be regarded as nothing special. There are a number of pre-determined styles categorised as: Sexy, Elegant, Pure and Sport. Each style involves an array of accessories. While these styles aren't exclusive to Japan, style categories are quite common in the Japanese fashion industry with websites such as Japanesestreets.com using such tags to identify style types. Many Japanese fashion magazines are constructed with the sole purpose of reaching one specific audience - for example: according to a Japanese fashion magazine guide on livejournal (ryuukou style 2009) magazines Pichi Lemon and Love Berry are aimed at those interested in "cute" clothing elements, whereas Elle Girl or Seventeen have "sexy" elements in the Japanese market. While a choice of styles might be seen as suggesting that it's fun to experiment with fashion, the names of the styles clearly coincide with particular constructions of femininity in the context of Japanese popular culture. The exercise of choice based on the player's attempts to predict what the date character is likely to "prefer" encourages her to think in terms of male preferences in certain dress categories. She is rewarded for being willing to change her personal choices in order to attempt to please a man. The choices and behaviours that are rewarded or likely to be rewarded are never those that might involve resistance to conventional gender performance or rejection of accepted social and cultural values.

Having chosen her clothing and accessories, the player advances to the date meeting spot. After an exchange of polite pleasantries when first meeting with her date, if she has chosen to align with a particular style, her date will comment on liking or disliking it, clearly indicating his approval or disapproval. This is followed by an inner monologue in which the protagonist expresses her own happiness or how upset she is with the outcome of her choice. If the protagonist 
wears a certain outfit on the first date and receives great praise for her choices and therefore decides to wear the same outfit on the second date, she will not be praised, rather her date will comment negatively. In this way she also learns that men like you to change your outfits from date to date, but always with a view to pleasing them. As Monden (2014) observed in Japanese Fashion Cultures: Dress and Gender in Contemporary Japan, because of its ability to immediately identify a gendered body as either masculine of feminine, clothing is a fundamental component of gender performance. Constrained by the style types to certain ideas of what constitutes "feminine", the player chooses her outfits and then completes her performance by wearing it. Her date's reactions will indicate whether she has gained or lost points.

The player and her date advance to the main date component. If the date involves going to see a movie, for example, the player will then watch a cutscene of the movie theatre and a small part of the movie. It is interesting to note that this main component of the date allows no option for game play even though most players probably consider it the most significant part of the date. Although the date invitation was to see a movie together, the seeing of the movie contributes nothing to the outcome of the date in terms of points allocated. Other choices for types of dates feature the same kind of player passivity - that is, the scene is only there to contribute to the "realness" of the representation of a date. The removal of player control during the main date event thus puts further emphasis on the events either side of it - the choice of clothing, and, as outlined below, the choice of response to the movie (or other date type). Both of these player choices rely heavily on pleasing the male.

With the main date component complete, the date asks the player to respond to a question about the component: that is, if the player and her date watched a movie, the date will ask about the movie. The player's choices of answers are equivalent to "like," "not fussed/ indifferent," or "didn't like.” Significantly for this analysis, she is commenting on what she thought about the movie, not what she thought of her date. The question and response are designed to enable 
her date to make another judgement about her. If she chooses the answer that aligns with how her date felt about the movie, he will express happiness. Having pleased her date, the protagonist will also be pleased. However, if the player chooses differently to her date, he will seem unhappy and the protagonist's inner monologue will follow suit. Here we can see that the female protagonist needs to express views that accord with the character she is dating or he will make his displeasure clear.

This feature is so central, and also so frustrating, that it is common practice for players to save their games just before dates, in order to reload their previous saves if a date is not pleased with the answers given. This allows a player to re-load their game in a further attempt to answer in a fashion more acceptable to the character's date. Reloading a save is so common in the dating simulator/visual novel community that not only is it recommended as a tip on most available walkthroughs for new players, such as Melissa Tan's Tokimeki Memorial Girl's Side walkthrough on Gamefaqs.com (2007), it also makes an appearance in quite a few anime series such as ???????? ("I don't have many friends"), when the character Sena, who plays a lot of dating simulators, comments when she upsets Kobato that it is unfair that in real life she can't reload her last save. While in a game such tactics are deployed in order to accumulate more points, in achieving those points female players are reminded that they are rewarded for pleasing a man, and that they will please a man by responding to experiences in ways that accord with his views, rather than according to their own taste or feelings.

Laura Mulvey (1975) was among those who, early in the history of feminist media studies, explained how the operation of the male gaze means that women may never escape the patriarchal culture in which they exist and so their identity and worth remain determined by how they are viewed by men. Although the Tokimeki Memorial Girl's Side is created with a female protagonist, the creators of the game are predominantly male. It is clear that while the game envisages a female audience, it reflects male ideals of what that female audience would "like," or perhaps should "like." Such processes ensure that 
the female protagonist on the screen is still constructed by the male gaze. Tokimeki Memorial Girl's Side depends on game mechanics that involve male suitors critiquing female protagonists through visual and verbal representations of displeasure or pleasure, approval or disapproval, which simultaneously indicate how the points are being allocated for or against players. The importance placed on meeting a suitor's expectations of desired traits, and the constant feature of the feminine protagonist relying on men for information about herself, both unquestioningly assume the centrality of the male gaze in shaping feminine subjectivity. The player who might, for example, enjoy wearing jeans and going to horror movies now, in the game, chooses to wear summer dresses and watch action movies in order to please her date. Both appearance and preferences are moulded by what is considered desirable by her date. Once again, the extent to which this might or might not reinforce heteronormative gender performance among Japanese or Western girls might vary between cultures and in different age groups, but at the very least the male gaze has to be taken to be the normative gaze if the game's narrative arc is to make any sense to the player and if the player is to "succeed" in the game.

Dating simulator games are prime sites for consideration of issues of techno-intimacy (Allison 2006), or the ways in which actual people form relationships with electronic objects and beings. Allison highlights a particularly striking degree of techno-intimacy in Japanese culture, including in the attitudes of Japanese culture towards machinery, and the habit of referring to it as if it were alive. She illustrates this with reference to products designed for physical as well as virtual techno-intimacy:

...intimate play goods are machines used for play and instruction and also for communication and companionship. Significantly, these devices are also said to be 'healing' in rhetoric that assumes players are already wounded: physically on edge, overworked, stressed out. Being touched by another, albeit a machine, is soothing: the s(t)imulation of social intercourse. (2006, p. 190) 
The principal aim of these single-player dating games is to encourage the player to become so infatuated with a character within the game that she will compete with herself in order to win the attentions of the character. Kennedy (2002, p. 8) observes that "people have always invested emotionally in literary, film and television characters.” This is no different with video game characters. If the player, feeling attracted to a particular character, wants to achieve the "good ending" with that character, she will need to put aside her own personal preferences, likes and dislikes in order to accommodate the preferences of her date. In this sense, the player's relationship with herself is compromised by the choices she makes in order to succeed in the virtual relationship/s she pursues in the game.

In dating simulators the player can form an intense emotional engagement despite the fact that the relationship is with a digital date and potential partner. These virtual relationships between a player and a virtual body can evoke any number of the player's emotions, including those expected during a "real" relationship. The formation of techno-intimacy is an expected outcome when the player engages with this game, however while the game can evoke positive and affectionate feelings between a player and character, it can just as readily cause feelings that are potentially harmful. This is particularly clear in Tokimeki Memorial Girl's Side given the extent to which a player's self-esteem, self-image and feelings of self-worth can be strongly affected by the actions of her date in response to her decisions.

If a character disapproves of her choices during a date, she is also likely to respond with a sense of discomfort or displeasure by opposing the date's thoughts. Negative and harmful gender norms are reinforced through game mechanics that either reward or punish the player's choices. If the player conforms to the date's opinion, he smiles and she advances, but if she disagrees or rebels, he frowns and her play/virtual relationship remains static or even regresses in some instances. Even players who are not heavily invested in the game may come to start associating their own self-worth with ingame stats: she might come to think about herself in terms of "real life 
stats" related to body image and successful performance of normative gender expectations. Many women across differing ethnicities, cultures and countries already believe that their perceived physical appearance is an indicator of their self-worth (Horn et al. 2011). The game is reinforcing pre-existing and culturally instilled genderoriented anxieties for a new generation of Japanese girls - as well as others who might play it. It invites them to attach their selfworth to the perceived opinions of others, and particularly, to the perceived opinions of men. The game acts as a platform of play to rehearse gender roles confined by the coded space of the creators, like Wohlwend's (2012, p. 7) take on the Disney Princess brand, the "always beautiful, self-sacrificing ingénue who never loses sight of her goal: to attract the hero.” Players of Tokimeki Memorial Girl's Side, especially the young audience to whom it's directed and in whose day to day life-worlds of school and adolescent interactions it is set, not only bring their existing cultural assumptions to the game, and modify them in response to the game, but can also model expected behaviour and norms from this game in "real" life situations. By keying in to "real world" dilemmas that many young women experience intensely, the game generates suggested responses that become readily available in the real world. The extent to which the game evokes emotions within the player may see that same player bring constructed emotional perceptions shaped in the game into her actual life. This, in turn, means that many players could come to understand their self-worth and participation in intimate situations even more strongly than ever in terms of whether or not they measure up to ideals dictated by the male gaze.

Regardless of girls and women being the players with "control” in Tokimeki Memorial Girl's Side, the game necessarily positions them as submissive and subordinate through game mechanics that determine expectations and penalise choices that don't align with normative Japanese social expectations, many of which are still based strongly in patriarchal values. For an experienced non-Japanesespeaking gamer, it is quite possible to work out the basic gameplay without any Japanese language, and thus, anyone with basic Japanese language skills can readily navigate the gameplay's particular 
combination of written text, visual representations and icons. Some Western players who engage with the game in Japanese might have their still-forming gender performance influenced while others might find aspects of the game play difficult to negotiate because they are unfamiliar with the social and cultural norms on which it so strongly relies. At the same time, it is clear that if this game is translated and distributed for Western audiences, its gendered assumptions and aspects of its broader social context are likely to present major difficulties for cross-cultural interpretation. For the time being, it is important for us to consider the game as a consumable text in its original form, to think carefully about its popularity among young women in its culture of origin and to come to terms with the range of potential effects among non-Japanese-speaking gamers many of whom are dedicated fans of Japanese popular culture.

\section{The Other Girls in Your Social Circle}

In the game, there are four feminine friend characters in addition to the nine possible masculine suitors. These in-game girl friends are a welcome inclusion into the mix of characters and in the game's narrative trajectory: these girls offer you friendship while you are on the road to love. Each of the girls has distinctly different personalities, likes, and abilities. Sometimes, in the game, just spending time with friends can be fulfilling. After school you and your friends can walk home together and maybe even go to a café where you talk and learn more about each other. The game mechanics of friendship: time spent together, getting to know one another through dialogue choices, cheering you up if you are failing exams and so forth, help facilitate the formation of techno-intimacies between the player and NPCs (non-playable characters). This relationship formed is later called upon if the friend becomes a rival. The game would be more inclusive if the girls were not all confined to being your friends. It would have been nice if one of the female characters was a dateable option. Instead, the friends get to be rivals when it comes to their love interests in the potential suitors. Some fans of the series have even commented on community sites that they are more interested in their friends. For instance, on Tumblr there are remarks such as: 
"Karen is the best waifu” (technazzy-draws-crap) or "*asks otome game a question. Why can't I go out with her?” (tiffke). However, such discussion has had no apparent influence on successive versions of the game. Mia Consolvo (2003) discusses the extent to which traditional fairytale romance is heterosexual - how this is considered "natural", expected and desired. She also found that by controlling characters, people not only go on to perform that character's gender but also its sexual orientation. Given the extent to which Japanese cultural norms in relation to heteronormativity have been embedded in the rest of the game design, the lack of female dating options in Tokimeki Memorial Girl's Side is not at all surprising.

The girl friends are:

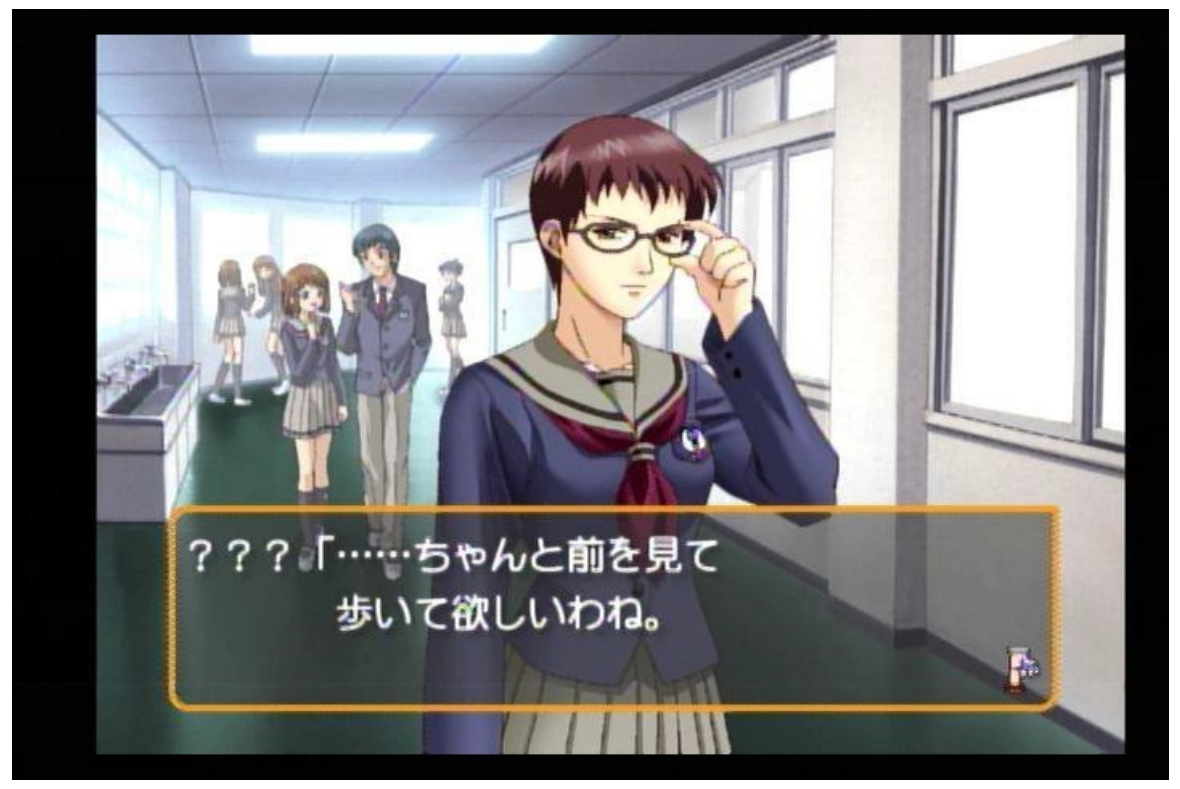

Figure 1: Name: Arisawa Shiho. Birthday: 20 January; Height: 168cm; Horoscope: Capricorn; Weight: Secret; Blood type: A; Part-time Job: Annery flower shop; Club: None; Rival in Love: Morimura Sakuya. 


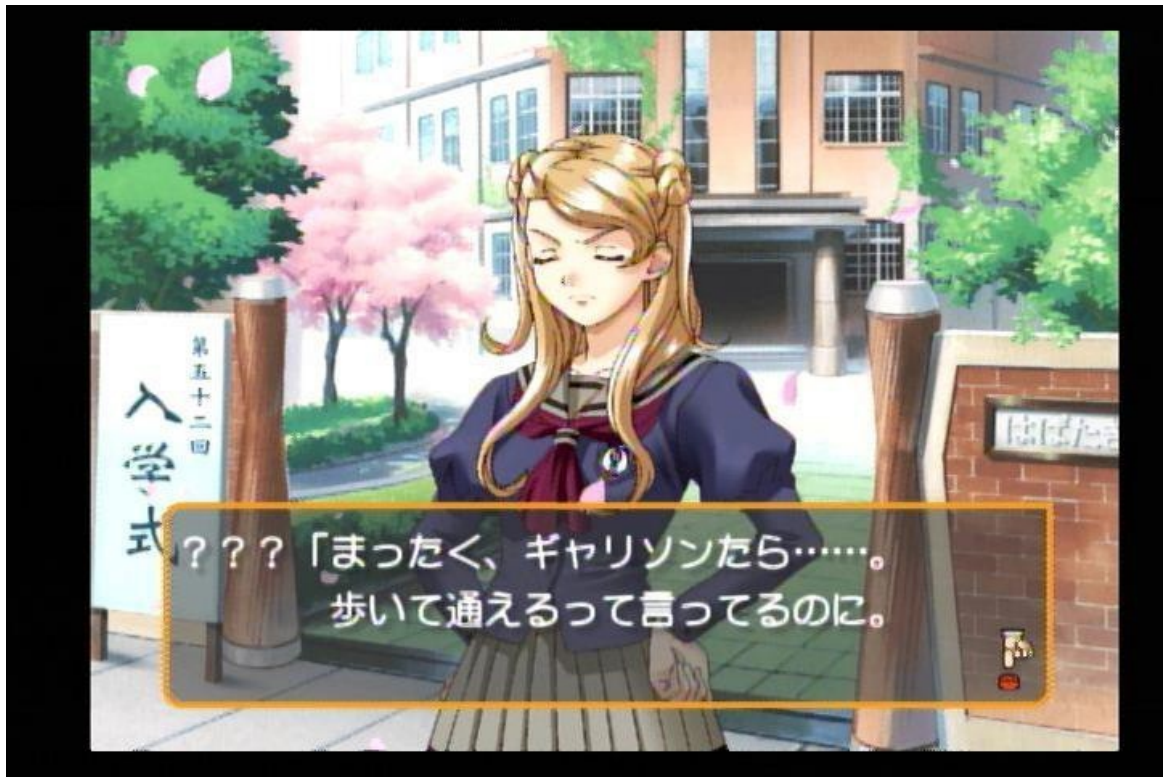

Figure 2: Name: Sudou Mizuki. Birthday: 16 July; Height: 157cm;

Horoscope: Cancer; Weight: Secret; Blood type: B; Part-time Job: None; Club: Tennis Club; Rival in love: Mihara Shiki.

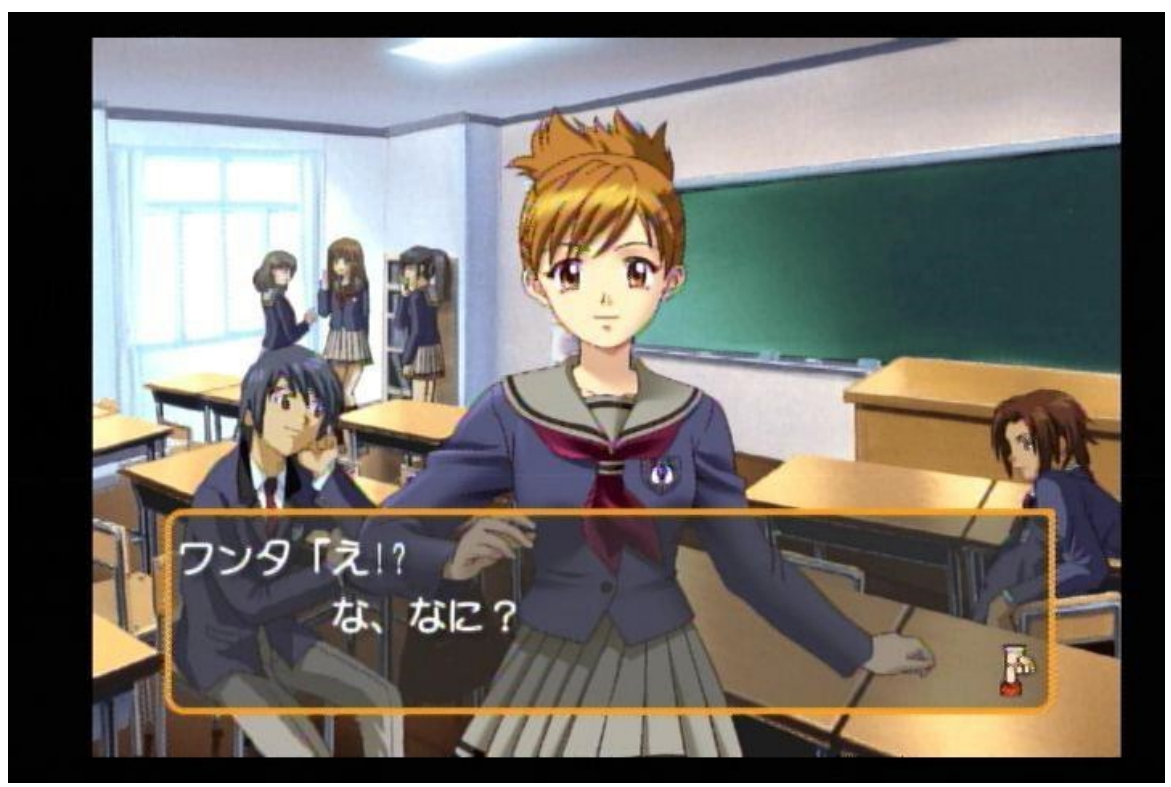


Figure 3: Name: Fujii Natsumi. Birthday: 18 December; Height: 159cm; Horoscope: Sagittarius; Weight: Secret; Blood type: AB; Part-time Job: Winning burger; Club: Cheerleading club; Rival in love: Kijou Madoko.

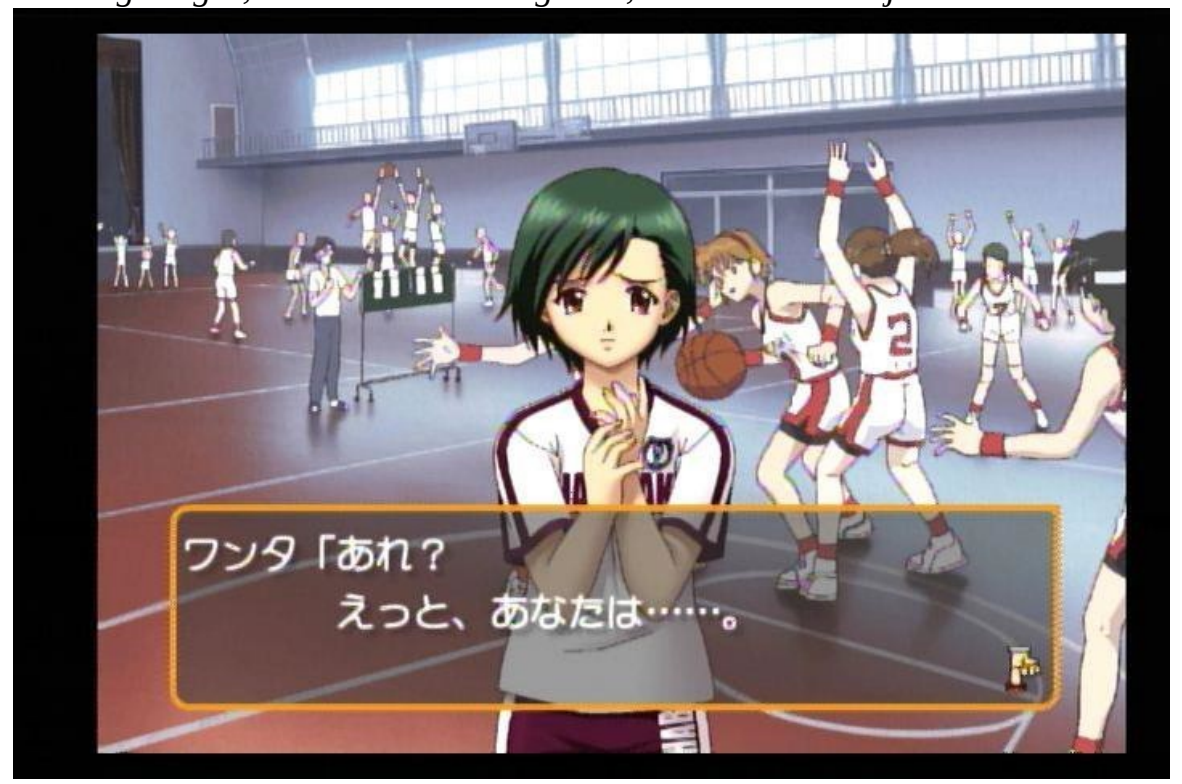

Figure 4: Name: Konno Tamami. Birthday: 5 June; Height: 151cm; Horoscope: Gemini; Weight: Secret; Blood type: O; Part time Job: None; Club: Basketball manager; Rival in love: Suzuka Kazama.

These characters are called "friends" and, as mentioned above, the play offers a range of opportunities to enjoy activities associated with friend relationships. However, if the player decides to date the same male character that her friend is interested in, then the friendship quickly deteriorates. These four friend/love rival girls are the only representations of women in the game (other than the protagonist), and yet they are frequently represented as petty, jealous and nasty. Even if you have reached "best friend" status with one of the girls after spending much of your time with her, if you start to date the male character she desires, she is quick to turn on you. It's entirely possible that years of in-game friendship created between you as player/protagonist and a particular friend are simply disregarded as soon as a man comes into the picture. Thus, the only relationships between women made possible by the game scenarios very quickly 
and easily deteriorate into conflict. In such situations, not one of the friends reacts in a way that is mature and beneficial for the player's happiness and well-being by behaving as a supportive friend. The game mechanics and narrative pathways invite female players to share the view that female friends are only friends while convenient, and that jealousy over men can easily destroy a relationship between women

When playing through the game for the first time, I dated Morimura Sayaka. My best friend of over a year (who was also interested in him) had a few nasty words for me before ignoring me. I was no longer able to select the option to spend time with her and activities that we would usually do together (e.g. studying) now depicted me alone. I was heartbroken. I felt as though I should never have expressed feelings towards the suitor I was interested in. In this sense, the impacts of techno-intimacy can feel "real” for a player - or rather, can be really felt. Jeni Lada similarly reports a loss of a best friend over a suitor in her description and review of her first play of Tokimeki Memorial Girl's Side Season 2:

Third Year: I must have screwed up. It all started around Valentine's Day. I made my super special chocolate for Hariya, even though I am awful at that game and needed all four tries to make perfect chocolate. (My low intelligence stat at work perhaps.) When I went to give it to him, Haruhi [her best friend] got all up in my face about it. I ignored her and gave it to him anyway. Then I went to save my game around the end of February, and my save file no longer showed my character with Hariya! I know! The horror! Instead of the two of us singing happily, it showed Hisoka and I sewing. I hadn't hung out with her since the end of first year! (Lada in Technology Tell on-line magazine, 2008)

That women are more jealous than men is a wide-spread assumption held by both genders regardless of there being no evidence to date to support this belief (Gordon 1996). Some research, however, has demonstrated that women are more likely to admit to being jealous 
than men and the researcher suggests that this explains why women are more associated with that emotion (Gordon 1996). Hostility towards other women due to jealousy is doubtless a learned behaviour that women adopt in order to conform to the socially constructed ideals of how a woman "should" behave. The development of an idea/ fantasy of the jealous woman is likely to have arisen from the ways in which many men are flattered by women's attention and even more flattered by the idea that two women will become rivals over them (Gordon 1996). When a woman turns on her friend due to jealousy, she seems to affirm that the man in question is more important to her relationally than any female friend, thus acknowledging the centrality of the male subject in patriarchal social and cultural settings. The game mechanics and narrative pathways in Tokimeki Memorial Girl's Side subscribe to these values: all of the game's girl friend characters will react in similarly negative ways towards a rival in love. Thus jealousy and its associated behaviours are normalised as expected emotional reactions from women.

I mentioned earlier that players often save the game before a date, and I certainly did. Saving game files is important for any video game, but I did it specifically so that if I received negative reactions to clothing and gave "wrong" responses to my date's questions, I could quit the game and re-load my save game in an attempt to receive a better outcome. That internet forums and websites that focus on dating simulators encourage the habit of saving and re-loading in order to get better outcomes (Konami 2012) suggests that players are not willing to be at the mercy of the game mechanics, instead adopting what could be thought of technologically resistant behaviours. Even once a player understands that in Tokimeki Memorial Girl's Side negative reactions from dates are not at all uncommon, those reactions can nevertheless take the player by surprise. For example, asked by my date how the movie was, and thinking I would flatter him for his choice (i.e. gain points), I responded with "it was good," only for him to become upset because he didn't like it and I was not agreeing with him (i.e. I lost points). Here, women are clearly coached to recognise that to advance in relationships with men, one must agree with men, even learn to second-guess their reactions in order to 
avoid disagreement. But women are also reminded that acts of actual or apparent individualism will be met with consequences. That is, the game not only suggests that the exercise of agency by women is unacceptable in heterosexual relationships, but also that resistant female subjects are likely to lose the game even when they think they've learnt how to play it.

\section{The Docile Woman and Male Marital Preferences}

Studies have shown that men find women who are less dominant to be more appealing for both casual and ongoing sexual relationships, and as marriage prospects (Berscheid and Regan 2008). Consideration of some heterosexual relationships involving cultural difference can provide further support for the fact that more men prefer docile partners. For instance, interracial marriages that involve an Asian husband and a Caucasian wife have a 59\% chance of ending in divorce, while of marriages between an Asian wife and a Caucasian husband only $4 \%$ tend to end in divorce. While the percentages differ somewhat between cultures, this trend pertains whether the host culture is Asian or Caucasian (Bratter and King 2008). There can be little doubt that such a stark difference in interracial marriage outcomes is largely due to the effects of differing values in relation to gender roles and the expectations of women, and of men, in different cultures. That interracial marriages containing a Caucasian wife have the highest divorce rate of interracial couples may be ascribed to the fact that most Western societies have a comparatively longer history of engagement with aspects of feminism and women's rights in contrast to most Asian countries - therefore Caucasian women are less likely to accept constraints on their liberty, and less likely to perform their gender in ways that present as docile, passive and emotionally dependent. Of course, class, levels of education, religious beliefs, degrees of social liberalism or conservatism, age difference, the presence or absence of children and many other factors cannot be overlooked in such an analysis, which is far too complex to undertake here. Some Western women still place men as "the head of the household" and view themselves as secondary. However, questions of difference also run the other way: the more educated and financially 
independent a woman is, regardless of culture, the more likely she is to be able to exercise agency in her relationships with men. Western women, though, have certainly been exposed to educational and social advantages, and legislative support for their freedoms, in greater proportions and for considerably longer than many nonWestern women. Another important caution in a discussion like this arises in relation to the apparent binary "Caucasian”/“Asian.” That mode of referring to race is problematic in itself given the rapidly escalating proportion of global citizens who are the products of multiracial partnerships, and given that the matter of cultural difference needs to be thought of in relation to "African," "Arabic," "Australian Indigenous” and all the other possible binaries. Further, race - itself a historically constructed category with no basis in biological fact - cannot be neatly assumed to be the same as ethnicity, and nor can ethnicity be neatly assumed to be a question of nationality.

We must also consider men's values in contributing to marital happiness and stability, or marital breakdown. Western men have been expected to come to terms with the changes in how the rights of women are positioned and enacted. Those unwilling to accept such changes now constitute a genuinely small minority in many countries - and some are probably the same men who seek out women for longterm partnership who they believe will have the "Asian” qualities of docility, passivity, unwillingness to contradict a man's views etc. And, of course, Asian men growing up with access to global popular culture, and those growing up in high immigration countries like Australia, often adopt values towards women that have become the mainstream cultural values of the West.

All of these things invite us to realise that questions of power relations between genders and how they play through in all kinds of settings are more complex, subtle, interconnected and messy than any stereotyped representation can ever account for. However, as this game suggests, Japan does not have the same kind "melting pot" of racial, ethnic, cultural and social backgrounds and expectations that exist in many other parts of the world. Despite globalising influences of many 
kinds, in terms of the social and cultural mix and the values carried in that mix, Japan remains to a considerable extent a majority culture - no longer a "monoculture" as people used to prefer to call it - but certainly a culture in which there is a very high degree of shared cultural information at the fundamental levels of values, ideologies, gender relations and language. This makes it in some respects all the more surprising, and in other respects completely unsurprising, that a significant amount of decidedly “out there” art, fashions, popular cultural movements, fan cultures and pioneering work in technocultural fields emerge from Japan. Dating sim games are part of such manifestations, yet embedded in them are values and practices that would be at home in Japan 100 years ago.

Increasing proportions of young, educated, hip and confident Japanese women do not actually share so-called "Japanese" "feminine" qualities. In the light of that observation about educated young women, it is interesting to recall that at one stage in a game, I approached a character for a date and was denied. I wasn't sure at first why I was rejected, so I continued with the game only to realise that I was rejected because a specific stat fell below the level that he considered as "minimal" for him to be interested in dating me. I required a study level of 50, but I had fallen to 45. After I reached level 50 again, he was happy to date me again, and even at times pursued me for dates. So, despite the fact that in reality it is the case that educated women are considerably more likely to resist being defined and constrained by a man, for at least one male character in the game, my insufficient interest in study became a reason to reject me, and my demonstration of a slightly higher level of interest in studying increased my desirability, even though the overall dynamic of the game discourages independence, intellectual evaluation, or holding one's own views. This sequence of events in the game play helped me to recognise that if I was to "succeed" in performing a desirable woman in the game, in future I had to ensure that I worked out what each male character I wanted to date preferred in my profile. I did this by extrapolating on the basis of my encounters with other aspects of his profile, characteristics and judgements. More effectively, though, I learned through multiple game playing what 
qualities and levels of achievement each male character required of me as a "minimum" for dates, and I would strive to accomplish that.

Reviewing the gameplay, a number of ironies and paradoxes emerge. The game mechanics, characterisations, representations and narrative strategies at times suggest that some of the boys and men like a girl who shows an interest in learning, but in the game play around the main component of the date, all of the boys and men reject a girl who has opinions of her own that don't agree with the boy's/man's opinions. After all, as Kennedy (2002, p. 3) observes, “'active’ or 'strong' female characters signify a potential threat to the masculine order.” A male character's desire for a girl with some education and an interest in study is, though, probably still all about the man. Such a girl is likely to graduate high school with good marks, maybe go to university, get a well-paid job while the couple is saving for house and children, and once she is at home with the children, she will be an interesting hostess and an appropriate accessory at important events. She will not embarrass him in conversation with his business associates, and neither will she be seen to contradict her husband or any of the men in her husband's circle. Once again, the woman's construction under the gaze is entirely a matter of the man's needs, desires, life choices, advancement in the world, and so on. There is an almost humorous irony present in performing one's gender in a video game designed for female players, given that gaming is still stereotypically considered a masculine activity. As Jenson and de Castell (2010, p. 54) state, “The powerful association of masculine subjects as gamers and game designers as well as the presumption of competence and ability have positioned women and girls unerringly as 'less able', 'less competent' and as 'casual' game players.”

There are many ways in which, in order to advance in the relationship, the female player/protagonist in Tokimeki Memorial Girl's Side is both constructed and expected to read herself through her date's eyes in order to conform willingly to his ideals regarding what is desirable in a girl or woman. So she subjects herself to the male gaze, just as I did in working out how to make my preferred dates find my protagonist more desirable. Returning to Mulvey, while this game is 
intended only for female players, thus having a female protagonist who has female friend characters, it is nevertheless only intelligible as a narrative sequence and its scenarios only make sense if it is read through male eyes - like Hollywood "chick flicks," various other kinds of romantic comedy as well as thrillers and even sci fi movies that make a female character the "main" character. We need only recall the famous scene in the first Alien film in which the courageous, tough as nails commanding officer of a merchant starship, in the form of Sigourney Weaver, removes her khaki overalls/space suit as the camera lingers over the various parts of her body left only in bikini knickers. Or we remember how Thelma and Louise - those now iconic women breaking free of the constraints of men, domesticity, suburbia, crappy jobs and the daily grind - can only, in the end, achieve real freedom by driving (triumphantly) over a cliff to their inevitable deaths. Girls - resistance is, finally, futile...

Since the player/protagonist of Tokimeki Memorial Girl's Side is not male, she must adopt a male viewpoint in order to work out how the male characters are expecting her to behave, just as I did. The female gaze (in this case, the player's perception of herself) is mediated by, filtered through, and in extreme circumstances, is inseparable from the male gaze. The player has been conditioned by all kinds of media product to see herself as men see her, and act accordingly. For most women, this unconscious double shuffle between male and female perspectives becomes "second nature." The game is based in a set of choices and scenarios that mean that the player must constantly try to "better" herself in the aspects of her daily life, character, dress, etc. that she learns are important to her suitors through the consequences of her actions as a player. The player's growing ability to read herself through her suitors' eyes (i.e. through the male gaze) makes up a large portion of game mechanics.

Tokimeki Memorial Girl's Side unabashedly relies on dominant, mainstream, male- centred, heteronormative Japanese values in its narrative structures - indeed, a player would not be able to engage effectively with the action if she resisted those values. In its use of such values, the game's scenario for a dating experience reinforces 
the construction of young Japanese women as docile, lacking in autonomous subjectivity and wanting to please a man. Exploring sexuality in "Hot dates and Fairy-Tale Romances", Mia Consolvo (2003, p. 172) notes that "representations of women and girls in games reapply many stereotypes of femininity and vulnerability found in more traditional medias." The exercise by the female protagonist of individual agency - by, for example, making choices based on her own desires and interests in the dating situation - will not enable the female player to succeed in the game by accumulating high points. The female player must concentrate on trying to read the desires, preferences and likely responses of the character who is her date, thus performing her gender in her persona as a protagonist as it is determined by her understanding of this fictional boy or man, which she can only do effectively by learning to be aware of what is expected of Japanese women and men in general.

The social and cultural reality that underpins the courting behaviours modelled in the game is, quite simply, that if you want to date someone, it is easiest to find out what he likes and then use that information to manipulate the situation in your favour. This can appear to put power into the hands of the player. Of course, in fact it reflects a reality in which there is a very considerable way to go before there is acceptance of the rights of girls and women to have actual power. In the meantime, the game teaches girls how to navigate the complexities of Japanese gender relations in effective ways for the context in which they live. If they do not achieve that navigation that is, if they do not learn to manipulate men by pandering to their tastes, opinions, decisions and sense of their own centrality - they will in all probability "lose the game," ending up alone in a virtual and real world that regards this as the worst fate that can befall a woman.

This paper has discussed how the gameplay of Tokimemi Memorial Girl's Side actively produces particular heteronormative perspectives on how girls and young women should enact femininity if they are to avoid being alone at the end of the game, and, for that matter, in life. 


\section{BIBLIOGRAPHY}

Allison, A. Millennial Monsters: Japanese Toys and the Global Imagination. Berkley and Los Angeles: University of California Press, 2006.

Berscheid, E. and P.C. Regan, The Mating Game: A Primer on Love, Sex and Marriage. Thousand Oaks CA: SAGE, 2008.

Bratter, J.L. and R. King, “'But Will It Last?’: Marital Instability Among Interracial and Same-Race Couples.” In Family Relations vol. 57, no. 2(2008): 160-171.

Butler, J. Undoing Gender. London and New York: Routledge, 2004.

Butler, J. Gender Trouble: Feminism and the Subversion of Identity. LondonandNew York:Routledge,2006.

Galbraith, P.W. “Bishojo Games: ‘Techno-Intimacy’ and the Virtual Human in Japan.” In Game Studies: The International Journal of Computer Game Research vol. 11, no. 2(2011).Viewed 4July2014, http://gamestudies.org/1102/articles/galbraith.

Girard, T., Silverblatt, R. and P. Korgaonkar, "Relationship of Type of Product, Shopping Orientations, and Demographics with Preference for Shopping on the Internet.” In Journal of Business and Psychology vol. 9(2003): 101-120.

Gordon, R. A. "The impact of ingratiation on judgements and evaluations: A meta-analytic investigation.” In Journal of Personality and Social Psychology vol. 71(1996): 54-70.

Griffith University. What is Bilingualism? Retrieved from http://www.griffith.edu.au/humanities-languages/school-languageslinguistics/research/bilingualism/what-is-bilingualism.

Hisashi Saito, ???????? “I don’t have many friends” [DVD], Madman entertainment, 2013. 
Horn, T., Newton, J. and J. Evers "Gender Conceptualizations in Female High School Seniors: Relationships with Global Self-Worth and Multiple Measures of Body Image.” In Sex Roles vol. 65, no. 5-6(2011): 383-396.

Iwao, S. Japanese Women: Traditional Image and Changing Reality. New York: The Free Press, 1992.

Japanese123. The Everything Japanese Guide; “Christmas Cake”. (2005) viewed 10 September 2013, http://www.japanese123.com/ christmascakes.htm.

Jenson, J. \& S. de Castell, “Gender, Simulation, and Gaming: Research Review and Redirections.” In Simulation \& Gaming vol. 41, no. 1(2010): 51-71.

Konami. Tokimeki Memorial Girl's Side [PS2]. SonyComputerEntertainment, 2002. Played 2013.

Kennedy, H. “Lara Croft: Feminist Icon or Cyberbimbo?” In Game Studies: The International Journal of Computer Game Research vol. 2, no. 2(2002) viewed 16 March 2015, http://gamestudies.org/0202/ kennedy/.

Konami, Tokimeki Memorial portal site, 2012. Viewed 10 August 2014, http://www.konami.jp/gs/game/tokimeki/.

Lada, J. “Important Importables: Tokimeki Memorial - Girl’s Side 2nd Season review" in Technology Tell on-line mag gaming section, 2008. http://www.technologytell.com/gaming/30351/importantimportables-tokimeki- memorial-girls-side-2nd-season-review/. Viewed 10 August 2014,

Lo Bianco, J. Second Languages and Australian Schooling. (2009) http://www.acer.edu.au/documents/AER_54-

SecondLanguagesAndAustralianSchooling.pdf. 
Monden, M. Japanese Fashion Cultures: Dress and Gender in Contemporary Japan, London: Bloomsbury Academic,2014.

Mulvey, L. "Visual Pleasure and Narrative Cinema.” In Screen vol. 16, no. 3(1975): 6-18.

MacCallum-Stewart, E. “'Take That, Bitches!'” Refiguring Lara Croft in Feminist Game Narratives.” In Game Studies: The International Journal of Computer Game Research vol. 14, no. 2(2014). Viewed 16 March 2015, http://gamestudies.org/1402/ articles/maccallumstewart.

Scott, R. Alien [DVD], 20th Century Fox, 1979.

Scott, R. Thelma and Louise [DVD], Metro-Goldwyn-Mayer, 1991.

Saho, M. "Equal sexual and employment rights for Japanese women.” Japanese Society Today: perspectives on tradition and change, edited by K. Ishidō, D. Myers pp. 177-182. Brisbane: Central Queensland University Press, 1995.

Tan, M. Walkthrough at: http://www.gamefaqs.com/ds/ 934799-tokimeki-memorial-girls-side-1st-love/faqs/48851.

Tehnazzy draws crap, Tumblrpage, http://tehnazzy-drawscrap.tumblr.com/post/90772537887/karens-the-best-husbandowaifu-sorry-sakurai

Tiffke, Tumblr page, http://tiffke.tumblr.com/

Tumblr: https://www.tumblr.com/search/tmgs3.

Walkerdine, V. "Femininity as Performance." In Oxford Review of Education vol. 15 no. 3(1989): 267-279.

Wohlwend, K. “The Boys who would be Princesses: Playing with Gender Identity Intertexts in Disney Princess.” In Gender and Education vol. 24, no. 6, (2012): 593-610. 